\title{
通電加熱処理における 炭素綫維比抵抗の温度一時間換算
}

高久 明, 万願寺拓秋, 塩谷正俊

\author{
(平成6年 1月 19 日受理)
Temperature-Time Superposition of Resistivity of Carbon Fibers during Heat-treatment by Direct Currenting

\author{
Akira Takaku, Takuaki Manganzi and Masatoshi Shioya \\ Department of Organic and Polymeric Materials \\ Tokyo Institute of Technology \\ 2-12-1, O-okayama, Meguro-ku, Tokyo 152, Japan
}

\begin{abstract}
The changes in the resistivity of polyacrylonitrile(PAN)- and pitch-based carbon fibers during isothermal hear-treatment by direct currenting were studied in the temperature range from 1200 to $2000^{\circ} \mathrm{C}$. By applying temperature-time superposition, smooth composite curves were obtained from the resistivity versus time curves at various temperatures. From these composite curves, the changes in the resistivity when the temperature was increased at a constant rate were calculated. The results of calculation approximated well the changes in the resistivity with temperature experimentally measured. Apparent activation energies of about 908 and $838 \mathrm{~kJ} / \mathrm{mol}$ were calculated respectively for PAN- and pitch-based carbon fibers from the relation between the shift factor used for the temperature-time superposition and the surface temperature of tow. The influence of temperature distribution in tow cross-section on apparent activation energy is considered to be small. The variation of resistivity with time at a constant heat-treatment temperature was assumed as a superposition of first-order rate processes, and a rate constant spectrum was calculated.
\end{abstract}

KEYWORDS: Direct currenting, Carbon fiber, Temperature-time superposition, Heat-treatment, Resistivity

\section{1. 緒言}

炭素材料の熱処理による構造形成過程は熱処理温度お よび時間に依存する速度過程であると理解されている。 Fischbachは，熱分解炭素1)およびピッチコークス2)の高 温における黒鉛化を調へ，熱処理による構造形成の速度

東京工業大学有機材料工学科: $\mp 152$ 東京都目黒区大岡 山2-12-1
過程を速度定数に分布をもった一次機構の重ね合わせと して表せること, および構造形成温度一時間換算則を適 用することによって構造形成の温度一時間依存性を系統 的に説明できることを報告している。温度一時間換算則 は多くの研究者によって炭素材料の熱処理に関する研究 に応用されており3)-5)，それらの結果はFischbachの総 説 $^{6)}$ に詳しく述べられている。

炭素緎維の力学的性質や構造は熱処理温度によって変 化する7)-9)。炭素織維の熱処理における構造形成過程 
Table 1 Characteristics of carbon fibers used for measurements.

\begin{tabular}{lcc}
\hline & \multicolumn{2}{c}{ Carbon fibers from } \\
\cline { 2 - 3 } & PAN & petroleum pitch \\
\hline Number of filaments & 3000 & 2000 \\
Linear density $(\mathrm{g} / \mathrm{m})$ & 0.203 & 0.309 \\
Density $\left(\mathrm{Mg} / \mathrm{m}^{3}\right)$ & 1.801 & 1.875 \\
$\begin{array}{l}\text { Maximum processing } \\
\text { temperature }\left({ }^{\circ} \mathrm{C}\right)\end{array}$ & 1250 & 1300 \\
\hline
\end{tabular}

も，他の炭素材料と同样に熱処理温度一時間に依存する 速度過程と考えられる。しかし，炭素瀻維の熱処理に関 して熱処理時間の効果を調べた報告は少ないようであ る。先に著者らは，炭素繊維トウに通電することによっ て発生する自己のジュール熱で織維を熱処理する場合に ついて，トゥ内温度分布 ${ }^{10}{ }^{1}$ よび熱処理瀻維の物性 ${ }^{11} に$ ついて調べた結果を報告した。通電加熱は短時間で瀻維 を所定の温度に加熱することが可能であり，このことは 一定熱処理温度において処理時間が構造形成に及はす効 果を調べるのに便利である。

本報告では, 通電加熱処理過程に扔ける炭素瀻維の比 抵抗変化について, 温度一時間換算則を検討した結果に ついて報告する。

\section{2. 実験}

\section{1 試料}

試料としてPAN系炭素瀻維トウと石油ピッチからのメ ソフェーズピッチ系炭素繊維トゥを用いた。これらの瀻 維が製造過程で受けた最高熱処理温度および主な特性を Table 1に示す。

\section{2 実験装置}

実験装置の概要をFig.1に示す。耐熱ガラス管内に4個 の黑鉛製プーリ(直径 $2 \mathrm{~cm})$ を設け，これらに接して $7.8 \mathrm{~N}$ の一定張力で炭素繊維トウを張った。トウには, フィラ メントを収束するために $5 \mathrm{~cm}$ に 1 回程度の撚りをかけ た。内側の一対のプーリを電極(電極間距離, $10 \mathrm{~cm}$ )とし てトゥに通電することにより，トウを所定の温度に加熱 した。ガラス管内には流量 $5 l / \mathrm{min}$ の窒素ガスを流した。 トウを通電加熱するに要した印加電圧と電流の測定值を 所定の時間間隔でマイクロコンピュー夕に取り込み, 解 析に供した。

トウの表面温度の測定はガラス管の外部から赤外放射 温度計(Minolta IR-630)を用いて行った。ガラス管によ る測定光(波長, $0.8 \sim 1.1 \mu \mathrm{m}$ )の吸収は無視した。

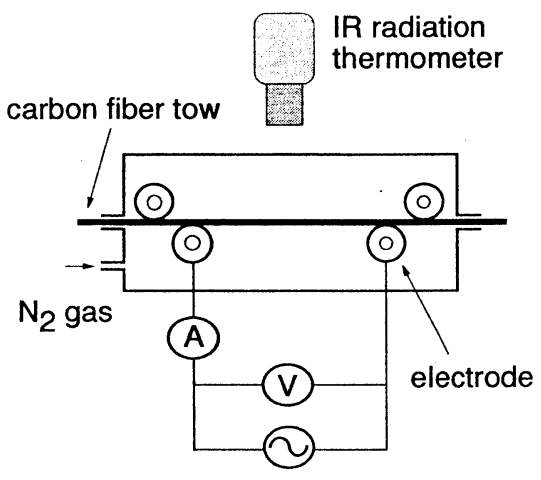

Fig.1 Experimental apparatus for heat-treatment of carbon fibers by direct currenting.

\section{3 測定}

(1) 定温熱処理過程における測定

ガラス管内の空気を十分に窒素ガスで置換してから， トウを $600^{\circ} \mathrm{C}$ に通電加熱し, この状態に 10 分間保持し た。次いでトウ温度を所定の温度まで急邀に上昇させた 後, 温度を一定に保つのに要する印加電圧と電流の時間 変化を測定した。

\section{(2) 昇温熱処理過程における測定}

通電加熱によりトウの温度を $600^{\circ} \mathrm{Cに} 10$ 分間保持して から， $1000^{\circ} \mathrm{C}$ な゙急激に上昇させ，次いでトウを昇温速 度約 $100^{\circ} \mathrm{C} / \mathrm{min}$ で昇温させながら, 所要の電圧と電流を 測定した。

\section{3. 結果および考察}

\section{1 定温熱処理過程における見掛けの比抵抗変化}

トウを所定の温度に通電加熱するに要した電圧 $E$ と電 流Iから，トウの見掛けの比抵抗 $\omega$ を次式により求めた。

$$
\omega=\frac{E S}{I L}
$$

ここで, $S$ はトウを構成する炭素緎維の初期断面積, $L$ は電極間のトウの長さである。

種々の熱処理温度におけるPAN系およびピッチ系炭素 瀻維の比抵抗 $\omega$ は, 熱処理時間 $t$ の経過に伴って指数関数 的に低下する傾向を示した。

Fig.2および3にそれぞれPAN系およびピッチ系炭素瀻 維の $\log \omega-\log t$ 線図を示す。これらの線図において，低温 における長時間域の変化は, 高温における短時間域の挙 動に相当すると見られる。そこで，任意の温度 $T$ におけ る熱処理時間 $t$ と基準温度 $T_{\mathrm{o}}$ における熱処理時間 $t_{\mathrm{o}}$ の間 に, $\kappa(T)$ を温度のみに依存する係数として次式の温度一 時間換算則を仮定する。 


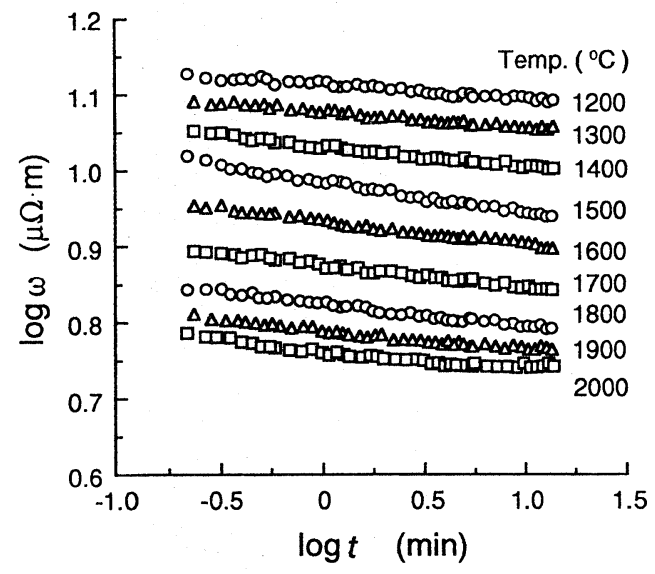

Fig.2 Variation of the logarithm of resistivity $\omega$ with the logarithm of time $t$ at various temperatures for PAN-based carbon fibers. The numbers in the right hand side show the treatment temperatures.

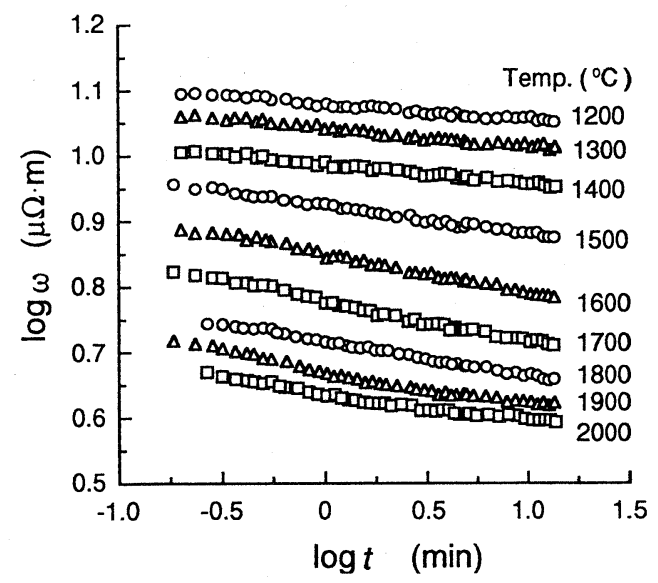

Fig.3 Variation of the logarithm of resistivity $\omega$ with the logarithm of time $t$ at various temperatures for pitch-based carbon fibers. The numbers in the right hand side show the treatment temperatures.

$$
t_{\mathrm{o}}=\kappa(T) t
$$

基準温度を $1200^{\circ} \mathrm{C}$ と, Fig. 2 および 3 の $\log \omega-\log t$ 線図 に式 (2)の換算則を適用して得た合成曲線を Fig.4に示 す。同図において重ね合わせの状態は良好であり，滑ら かな合成曲線が得られている。合成曲線の作成に用いた 換算因子 $\kappa(T)$ と温度の逆数の関係を Fig. 5 に○で示す。

\section{2 昇温熱処理過程における比抵抗変化}

式(2)の温度一時間換算則が成立するならば, 換算因 子 $\kappa(T)$ と温度の関係および一定熱処理温度における比抵

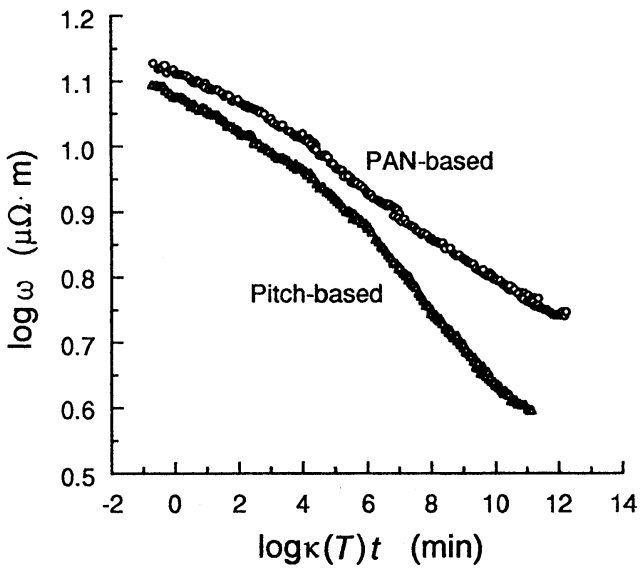

Fig.4 Composite curves of the logarithm of resistivity $\omega$ versus the logarithm of reduced time $\kappa(T) t$ at $1200^{\circ} \mathrm{C}$ for PAN- and pitch-based carbon fibers.

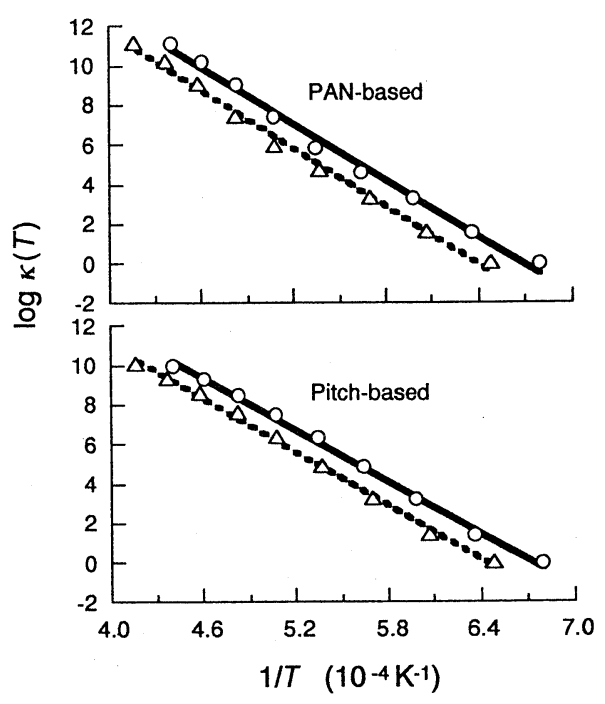

Fig.5 Plot of the logarithm of shift factor $\kappa(T)$ versus the reciprocal of $(O)$ surface and $(\Delta)$ average temperatures of tow $T$ for PAN- and pitch-based carbon fibers.

抗の時間変化の合成曲線から, 任意の温度プロフィール による熱処理過程における比抵抗の変化を予測すること ができる。熱処理温度 $T$ が時間 $t$ の関数として与えられる 場合, これと等価な処理を与える温度 $T_{\mathrm{o}}$ での処理時間 $\mathrm{t}_{\mathrm{o}}$ は,

$$
t_{\mathrm{o}}=\int_{0}^{t} \mathrm{\kappa}(T) \mathrm{dt}
$$

と表される。 


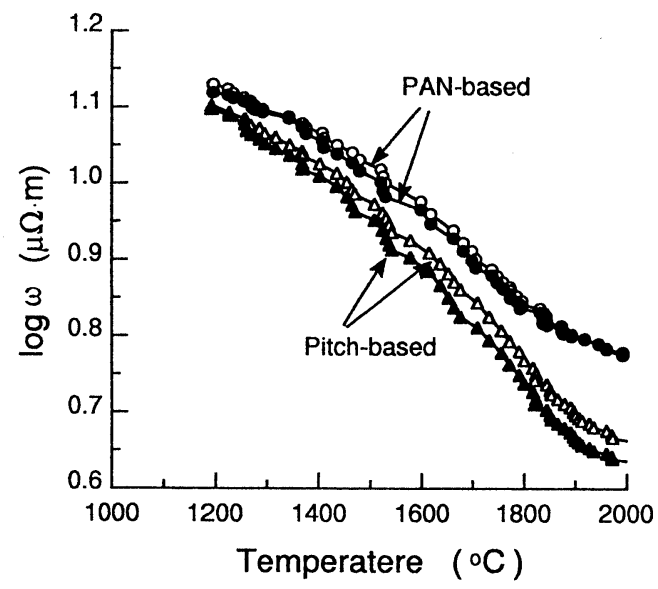

Fig.6 Variation of the logarithm of resistivity $\omega$ with temperature at an increasing temperature rate of about $100^{\circ} \mathrm{C} / \mathrm{min}$ in average; $(\bigcirc)$ experimental and (O) calculated values for PAN-based carbon fibers, and $(\triangle)$ experimental and $(\boldsymbol{\Delta})$ calculated values for pitch-based carbon fibers.

PAN 系およびピッチ系炭素瀻維について昇温実験を 行って得た比抵抗と温度の関係をFig.6に示す。同図に は, 実験に用いた熱処理温度プロフィール, $\log \kappa(T)-$ 温度関係および比抵抗の合成曲線から, 式(3)によって 算出した比抵抗と温度の関係も示した。計算值は実測值 をよく近似しているといえる。

\section{3 比抵抗の速度定数分布}

一定熱処理温度における比抵抗の時間変化を様々な速 度定数 $k$ をもつ一次機構の重ね合わせで表すと, 速度定 数 $k$ をもつ比抵抗成分の分布強度を $F(k)$ として， $\omega$ は次 式のように表される。

$$
\omega=\omega_{\infty}+\int_{-\infty}^{\infty} F(k) \exp (-k t) \mathrm{d} \ln k
$$

ここで， $\omega_{\infty}$ は熱処理時間が十分に長いときの比抵抗であ る。

温度 $T$ おび $T_{\mathrm{o}}$ における速度定数をそれぞれ $k$ および $k_{\mathrm{o}}$, 速度定数の分布強度をそれぞれ $F(k)$ および $F_{\mathrm{o}}\left(k_{\mathrm{o}}\right)$ とす ると，温度一時間換算則は，

$$
k_{\mathrm{o}}=\frac{k}{\kappa(T)}
$$

および

$$
F_{o}\left(k_{o}\right)=F(k)
$$

と表される。

比抵抗の合成曲線から速度定数の分布関数 $F(k)$ を求め るために，式(4)に含まれる指数関数を

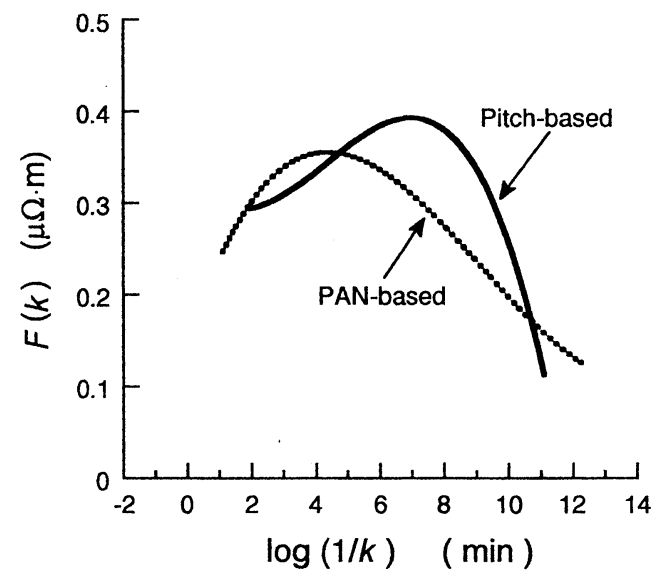

Fig.7 Rate constant spectra $F(k)$ versus the logarithm of reciprocal rate-constant $1 / k$ at $1200^{\circ} \mathrm{C}$ for PANand pitch-based carbon fibers.

$$
\exp (-k t)= \begin{cases}1-\frac{k}{2} t & \left(0 \leq t \leq \frac{2}{k}\right) \\ 0 & \left(t>\frac{2}{k}\right)\end{cases}
$$

と近似すると, $F(k)$ は

$$
F(k)=\left[-\frac{\partial \omega}{\partial(\ln t)}+\frac{\partial^{2} \omega}{\partial(\ln t)^{2}}\right]_{t=2 / k}
$$

と表される。基準温度を $1200^{\circ} \mathrm{C}$ とて求めたPAN系お よびピッチ系炭素緎維の $F(k)-\log (1 / k)$ 線図を Fig.7に示 す。PAN系およびピッチ系炭素緎維の速度定数の分布強 度は，それぞれ $1 / k \sim 10^{4}$ およ゙ $10^{6} \min に$ 分布のピークを 示している。

式(4)に示した速度定数の分布強度 $F(k)$ を有する試料 が温度 $T$ の熱処理に換算して処理時間 $t^{\prime}$ の前処理を受け た場合，この前処理を受けた試料についての熱処理温度 $T に お け る \omega の$ 変化は次式で与えられる。

$$
\omega=\omega_{\infty}+\int_{-\infty}^{\infty} F(k) \exp \left(-k\left\{t^{\prime}+t\right\}\right) \mathrm{d} \ln k
$$

したがって，この試料の速度定数の分布強度 $F^{\prime}(k)$ は

$$
F^{\prime}(k)=F(k) \exp \left(-k t^{\prime}\right)
$$

となる。すなわち, 同一の物質から出発して異なる熱履 歴を経た炭素の速度定数の分布強度は, 式(10)によって 相互に対応付けることができる。種々の炭素についての 速度定数の分布強度のデータを集積し, 式(10)の対応関 係に基づいたデータの整理を行うことにより，黒鉛化過 程の包括的な理解が可能になると考えられる。 


\section{4 見掛けの活性化エネルギー}

換算因子と温度の関俰において，Rを気体定数として 見掛けの活性化エネルギー $\Delta H_{\mathrm{a}}$ を

$$
\Delta H_{a}=-R \frac{\partial \ln \kappa(T)}{\partial T^{-1}}
$$

と定義すると, Fig.5 に実線で描いた直線の勾配から PAN 系炭素瀻維について $908 \mathrm{~kJ} / \mathrm{mol}$ ，ピッチ系炭素繊維 について $838 \mathrm{~kJ} / \mathrm{mol}$ が得られる。

炭素緎維卜ウを直接通電加熱した場合には, トウ表面 からの対流熱伝導と放射による熱損失によって，トウ内 部に温度分布が生じる。トウを半径 $r_{\mathrm{s}}$ の円柱とみなし，

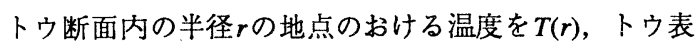
面温度を $T_{\mathrm{s}}$ とする。トウの発熱量および見掛けの熱伝導 率Kがトウ断面内で一定であるとすると, 通電加熱に要 する電力をWとして

$$
T(r)=T_{s}+\frac{W}{4 \pi L K}\left\{1-\left(\frac{r}{r_{s}}\right)^{2}\right\}
$$

と与えられる ${ }^{10)}$ 。ここで, トゥの平均温度 $\mathrm{T}_{\mathrm{av}}$ を

$$
T_{a v}=\frac{1}{\pi r_{s}^{2}} \int_{0}^{r_{s}} 2 \pi r T(r) \mathrm{d} r
$$

と定義すると，

$$
T_{a v}=T_{s}+\frac{W}{8 \pi L K}
$$

と表される。

式 (14)によって算出した平均温度の逆数に対して

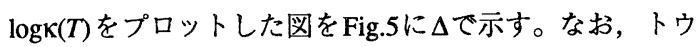
の熱伝導率 $K$ は温度によって変化するので, 本実験に用 いたものと同様のPAN系炭素繊維トゥについて実験に よって得た $K$ と温度の関係 ${ }^{10)}$ を用いて平均温度を算出し た。平均温度を用いた場合には, 見掛けの活性化エネル ギーとしてPAN系炭素織維について約 $939 \mathrm{~kJ} / \mathrm{mol}$, ピッ チ系炭素瀻維について約 $866 \mathrm{~kJ} / \mathrm{mol}$ が得られる。これら の值は, トゥ表面温度を用いて算出される見掛けの活性 化エネルギーよりも大きいが, 平均温度と表面温度を用 いた場合の差は約 $3 \%$ とさい。このことから，トゥ内 の温度分布が見掛けの活性化エネルギーに及ぼす影響は 小さいと推定される。

ピッチコークスについては, 多くの研究者によって, 熱処理による(002)面間隔, 積層網面のひろがりおよび 反磁性受磁率の変化に温度一時間換算則を適用すること により，見掛けの活性化エネルギーが求められている。 それらの結果では, 見掛けの活性化エネルギーとして熱 処理温度 $2000^{\circ} \mathrm{C}$ 以上では約 $1050 \mathrm{~kJ} / \mathrm{mol}$, 熱処理温度 $2000^{\circ} \mathrm{C}$ 以下では約 $630 \mathrm{~kJ} / \mathrm{mol}$ が得られている3)。また, 難

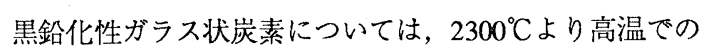
熱処理から約 $900 \mathrm{~kJ} / \mathrm{mol}$ が得られている ${ }^{12)}$ 。本報告での
熱処理は $1200 \sim 2000^{\circ} \mathrm{C}$ の温度域を対象としているが, 得 られた見掛けの活性化エネルギーは易黒鉛化性および難 黒鉛化性炭素の約 $2000^{\circ} \mathrm{C}$ 以上ての熱処理について報告さ れている值に近い。

\section{4. 結論}

PAN系およびピッチ系炭素瀻維を一定温度で直接通電 加熱処理することにより，比抵抗の時間変化を 1200 $2000^{\circ} \mathrm{C}$ の温度範囲で測定した。温度一時間換算則を適用 することにより，種々の熱処理温度における比抵抗一時 間関係から滑らかな合成曲線を得ることができた。この 合成曲線から, 昇温熱処理過程での比抵抗の変化を計算 した。計算結果は実験的に得た比抵抗の変化をよく近似 した。温度一時間換算因子とトウ表面温度の関係から算 出した見掛けの活性化エネルギーは, PAN系炭素瀻維で 約 $908 \mathrm{~kJ} / \mathrm{mol}$, ピッチ系炭素棫維では約 $838 \mathrm{~kJ} / \mathrm{mol}$ であ ク，プレカーサー物質の種類による差は小さい。見掛け の活性化エネルギーに及はすトウ内温度分布の影響は小 さいと推定される。一定熱処理温度における比抵抗の時 間変化が1次機構の重ね合わせで表されると考えて, 速 度定数分布スペクトルを算出した。

\section{文献}

1) D. B. Fischbach, Appl. Phys. Letters 3 (1963) 168170.

2) D. B. Fischbach, Nature 200 (1963) 1281-1283.

3) T. Noda, M. Inagaki and T. Sekiya, Carbon 3 (1965) $175-180$.

4) M. Inagaki, Y. Murase and T. Noda, J. Ceram. Assoc. Japan 76 (1968) 14-19.

5) H. Tanaka, Y. Kaburagi and S. Kimura, J. Mater. Sci. 13 (1978) 2555-2559.

6) D. B. Fischbach, Chemistry and Physics of Carbon Vol.7 (1968) p.1-105, Marcel Dekker, New York.

7) 進藤昭男, 大阪工業試験所報告 12 (1961) 110-118, 119-122.

8) W. Watt and W. Johnson, Appl. Polym. Symposia No.9 (1969) 215-227.

9) L. S. Singer, Carbon 16 (1978) 408-415.

10) 山本清志, 鞠谷雄士, 高久 明, 炭素 1991 [No.148] 142-150.

11) 山本清志, 鞠谷雄士, 高久明, 炭素 1991 [No.146] 8-14.

12) R. R. Saxena and R. H. Bragg, Carbon 16 (1978) 373-376. 